\title{
Models of abstract and real systems based on broken symmetry group
}

\author{
K.A. Gorshkov ${ }^{1,2,}$, V.G. Rau ${ }^{1}$, R.V. Filippov ${ }^{1}$, and S.M. Arakelian ${ }^{3}$ \\ ${ }^{1}$ Vladimir Branch of the Russian Presidential Academy of National Economy and Public \\ Administration, 59a Gorky Street, Vladimir, 600017, Russia \\ ${ }^{2}$ National Research University Higher School of Economics, 20 Myasnitskaya Street, Moscow, \\ 101000, Russia \\ ${ }^{3}$ Vladimir State University n.a. A.G. and N.G. Stoletovs, 87 Gorky Street, Vladimir, 600000, Russia
}

\begin{abstract}
This article shows that symmetry groups as well as broken symmetry groups in natural and abstract mathematical may be used as models of development and evolution objects while describing the states and transformations of such systems. It also demonstrates "visualization" methods of $\mathrm{PbTe}$ nanostructures, $\mathrm{ZN}$ arithmetic, Galois group for the roots of a fourth degree polynomial, and DNA structure in the framework of category theory.
\end{abstract}

\section{Introduction}

The mathematical models related to category theory are found increasingly necessary in research of natural systems, objects and their structures in the process of growth and development [1]. The examples of categories in mathematics are: Set - the category of sets, Grp - the category of groups, their objects are groups, and morphisms are mappings preserving the group structure (group homomorphisms), VectK - the category of vector spaces [2].

Commutative diagrams are the standard way to describe statements of category theory. Any commutative diagram is a directed graph which vertices contain objects, the arrows are morphisms, and the result of the composition of the arrows does not depend on the chosen path.

The structures of directed graphs perform role of commutative diagrams in our studies of symmetry groups (SGrp) and broken symmetry groups (BSGrp). These graphs are shown as the multitude of vertices (points) - structural elements, and morphisms (transformations) are shown as the arrows. Systems's representing using category theory allows one not only to calculate the number of their elements, but also to visualize in diagrams and directed graphs. The constructing of composition tables for the elements of symmetry groups and broken symmetry groups is a necessary element of preliminary "digitization" of information. The space where we will perform the subsequent visualization of abstract operations for the elements we call the "space of possibilities".

\footnotetext{
${ }^{*}$ Corresponding author: godograf@list.ru
} 


\section{Nanocluster PbTe}

Symmetry groups are determined by the systems of axioms of associativity, the inverse and the neutral elements. Neglecting of any of the existence axioms of a symmetry group breaks the symmetry of the system and generates processes and phenomena in this system according to the P. Curie principle [3]. Any process in nature is generated by the symmetry breaking of the system. The Curie principle reflects the causal relationship of all kinds of changes occurring in real systems - from natural to social and intellectual ones. For example, the quantum theory of non-Abelian gauge fields with spontaneously broken symmetry serves as the basis of studies of fundamental natural processes at the microworld level $[4,5]$.

In the work [6], the authors proposed a method for producing clusters of PbTe nanoparticles with an average size of 5-30 $\mathrm{nm}$ while the action of the continuous laser radiation of the near-IR range of moderate intensity (up to $106 \mathrm{~W} / \mathrm{cm} 2$ ) on a crystalline target placed into glycerol. In this case the appearance of a crystalline nucleus and a PbTe nanocluster were the result of the symmetry breaking of the material under the laser irradiation and subsequent self-assembly from dipoles $(\mathrm{PbTe}) \mathrm{n}(\mathrm{n}=1.2)$.

$\mathrm{PbTe}$ nanocluster growth was modeled in two ways: when PbTe dipoles were imaged as a single element (ball) and when dimers ( $\mathrm{PbTe}) 2$ composed of two dipoles were represented by a dot (ball). The process of a similar calculation of layer-by-layer growth of the $\mathrm{NaCl}$ structure, performed by usage of the program [7], was published by the authors in the research [8].

In the case of PbTe molecules, from the point of view of crystallography, the correct point system corresponding to the bcc or fcc lattice is formed, as in many metals. With the growth of the structure the shape of the smallest "point" cluster can lead to a crystalline nucleus in the form of a cuboctahedron (figure 1a) or a cube (figure 1b), as the calculation shows.

The number of cuboctahedron growth spheres (20 spheres) chosen to demonstrate this method, with a lattice period of $6.45 \AA$, corresponded to the same size $(12.9 \mathrm{~nm})$ of the cuboctahedron edge (in cubic syngony). The number of molecules on the $k$-th layer surface of a growth polyhedron was determined, in this case, by the formula $10 k^{2}+2$. Thus, to increase the size of the cuboctahedron up to the experimentally observed values $(8-30 \mathrm{~nm})$, it was sufficient to use from 20 to 50 layers or coordination "spheres" in the calculation.

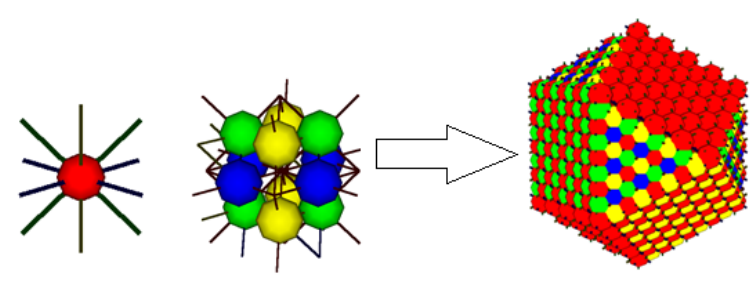

a

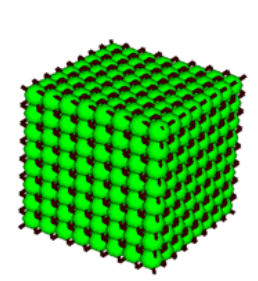

b

Fig. 1. Models of layer-by-layer growth of the PbTe cluster during its growth by dipoles in the form of the cuboctahedron (a) and dimers in the form of the cube (b).

The numerical sequence $N_{j}=\sum_{k=1}^{i}\left(10 k^{2}+2\right)$ of the cluster structure growth based on dipoles in the form of the cuboctahedron, shown in figure 1a, led to "magic-numbers" in nanotechnology [9]. Similar sequences of growth numbers were observed for some other atomic and molecular clusters. Each time, at the beginning of the face growth, when moving from a cluster of one size to another size, its symmetry was broken at the beginning 
and then restored when the surface was completely covered by atoms (molecules) of the next layer. In the same way, the growth of a cube-shaped nanocluster (figure $1 \mathrm{~b}$ ) with magic-numbers's growth was predicted theoretically: $N_{j}=\sum_{k=1}^{i}\left(6 k^{2}+2\right)$ with the growth of the structure based on the dimer (PbTe)2 (from two dipoles).

Electron microscopy showed that the "cubic" structure of layer-by-layer growth of nanocluster $(\mathrm{PbTe}) 2$ growing on the basis of the dimer was preferable (figure $1 \mathrm{~b}$ ) in the described experiment, performed by breaking the symmetry of the material using the femtosecond laser. Obviously, the practical and theoretical difficulties of forecasting that arose in this kind of research required a quest for the relationship between the symmetry of the system and its breaking.

\section{Algebraic objects}

The terminology of the broken symmetry group was first introduced in [10], and then dedicated in the article [11], which was devoted to the analysis of the rearrangement of intracomplex hydrogen bonds in the structure of the complex cation [Me (urea)6] $+2,+3$.

Next, were viewed several examples for the calculation and visualization of group symmetry and broken symmetry groups, starting with mathematical structures.

\subsection{Example 1. The finite Galois group of roots of a polynomial of degree 4}

According to group theory [12], an equation of the n-th degree has n-roots. Changing the form of the equation by choosing the appropriate transformations does not change the solutions (roots) of the equation, but only their "permutation", that belongs to the symmetry of the Galois group. In particular, the polynomial equation $P(x)=x^{4}+x^{3}+x^{2}+x+1=0$ has 4 roots. Transformations of the form $\mathrm{y}=\mathrm{xn}$ of the roots of the equation induce a fourth-order finite group with elements: (1243), (1342), (14)(23) and $1=(1234)$. These transformations make it possible to obtain some roots of the equation from others, for example, the notation (1243) means that the first root is transferred to the second, the second - to the fourth, the fourth - to the third, and the third to the first: $1 \rightarrow 2 \rightarrow 4 \rightarrow 3 \rightarrow 1$. The group can be "visualized" after moving to the record of substitutions (on the bottom line of the two-line transformation matrix) from the first transformation $(1243)-\mathrm{g}[1]=(1302)$, selected as the beginning of calculations and calculation of the Cayley table using the software "MATRIX" [13]. The calculation for this program always starts with the number "0", so the root translation can be set by substitution: $g[1]=\left(\begin{array}{l}0123 \\ 1302\end{array}\right)$. The calculation results are presented in table 1 .

Table 1. Cayley table of a finite Galois group for the roots of the equation $\mathrm{P}(\mathrm{x})=0$.

\begin{tabular}{|l|l|l|}
\hline Substitutions & Multiplication table & Cycles \\
\hline $\mathrm{g}[0]=(0123)$ & $\mathrm{g}[0] \mathrm{g}[1] \mathrm{g}[2] \mathrm{g}[3]$ & $(1234)=\mathbf{1}$ \\
\hline $\mathrm{g}[1]=(1302)$ & $\mathrm{g}[1] \mathrm{g}[2] \mathrm{g}[3] \mathrm{g}[0]$ & $(1243)$ \\
\hline $\mathrm{g}[2]=(3210)$ & $\mathrm{g}[2] \mathrm{g}[3] \mathrm{g}[0] \mathrm{g}[1]$ & $(14)(23)$ \\
\hline $\mathrm{g}[3]=(2031)$ & $\mathrm{g}[3] \mathrm{g}[0] \mathrm{g}[1] \mathrm{g}[2]$ & $(1342)$ \\
\hline
\end{tabular}

The right column of the group elements (in subcycles) was added in order to coordinate the initial information (from elementary algebra courses) with the calculation table performed by us. Figure 2 showed the "visualization" of the transformation elements from Table 1 on the plane. 



Fig. 2. "Visualization" of the digraph structures of the finite Galois group (table 1) for the roots of the polynomial in the equation $P(x)=x^{4}+x^{3}+x^{2}+x+1=0$.

The analysis of the multiplication table leads to the conclusion that the calculated symmetry group is cyclic with the generating element $g[1]=(1302)$.

\subsection{Example 2. Symmetry groups and broken symmetry groups. Arithmetic $Z_{N}$}

Any finite arithmetic $Z_{N}$, with the numbers considered using modulo $N(\bmod N)$, can belong to a set with $\mathrm{N}$ divisors and a set $(\bmod p)$ with $\mathrm{N}$ without divisors and relate to primes $(N=p)$ [12]. Then we have two variants, with respect to symmetry.

Variant 1 . Arithmetic and symmetry group $Z_{7}$

The analysis of the multiplication table $(\bmod 7)$ showed that all the numbers in each row and each column form a "permutation" of numbers from 1 to 6 . It allowed us to conclude that the multiplication table belonged to the "Cayley table" of the symmetry group. Multiplication by " 0 " was not included in the permutation. We selected the third row of table 2 as an element of the generating group of binary products, that was, the permutation operation $g[1]=(0246135)$ shown in table 3 . Then we calculated the group using the software to verify the identity of the data recorded in these tables 2 and 3 . The operation $g[6]=(0000000)$ did not occur in the calculations, but it expanded the symmetry group and it was its "broken" one, since it was not a permutation (tables 2, 3).

The operation $\mathrm{g}[0]=(0123456)$ is the identity transformation or "identity element" of a group, which is almost never used in calculations.

Table 2. Residues from dividing by 7 the product of the corresponding numbers in the row and column.

\begin{tabular}{|l|l|l|l|l|l|l|l|}
\hline$*$ & 0 & 1 & 2 & 3 & 4 & 5 & 6 \\
\hline 0 & 0 & 0 & 0 & 0 & 0 & 0 & 0 \\
\hline 1 & 0 & 1 & 2 & 3 & 4 & 5 & 6 \\
\hline 2 & 0 & 2 & 4 & 6 & 1 & 3 & 5 \\
\hline 3 & 0 & 3 & 6 & 2 & 5 & 1 & 4 \\
\hline 4 & 0 & 4 & 1 & 5 & 2 & 6 & 3 \\
\hline 5 & 0 & 5 & 3 & 1 & 6 & 4 & 2 \\
\hline 6 & 0 & 6 & 5 & 4 & 3 & 2 & 1 \\
\hline
\end{tabular}


Table 3. Arithmetic $Z_{7}$ group symmetry in the software "MATRIX".

\begin{tabular}{|c|c|c|c|c|c|}
\hline 123456$)$ & $\mathrm{g}[0] \mathrm{g}[1]$ & $\mathrm{g}[2] \mathrm{g}[3]$ & $\mathrm{g}[4]$ & $\mathrm{g}[5]$ & $\mathrm{g}[6]$ \\
\hline 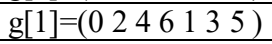 & $\mathrm{g}[1] \mathrm{g}[2]$ & $\mathrm{g}[0] \mathrm{g}[4]$ & $\mathrm{g}[5]$ & $\mathrm{g}[3]$ & $\mathrm{g}[6]$ \\
\hline $\mathrm{g}[2]=$ & $\mathrm{g}[2] \mathrm{g}[0]$ & $\mathrm{g}[1] \mathrm{g}[5]$ & $\mathrm{g}[3]$ & $\mathrm{g}[4]$ & $\mathrm{g}[6]$ \\
\hline $\mathrm{g}[3]=$ & $\mathrm{g}[3] \quad \mathrm{g}[4]$ & $\mathrm{g}[5] \mathrm{g}[1]$ & $\mathrm{g}[2]$ & $\mathrm{g}[0]$ & $\mathrm{g}[6]$ \\
\hline $\mathrm{g}[4]=\left(\begin{array}{lllllll}0 & 6 & 5 & 4 & 3 & 2 & 1\end{array}\right)$ & $\mathrm{g}[4]$ & $\mathrm{g}[3] \mathrm{g}[2]$ & $\mathrm{g}[0]$ & $\mathrm{g}[1]$ & $\mathrm{g}[6]$ \\
\hline  & $\mathrm{g}[5] \mathrm{g}[3]$ & $\mathrm{g}[4] \mathrm{g}[0]$ & $\mathrm{g}[1]$ & $\mathrm{g}[2]$ & $\mathrm{g}[6]$ \\
\hline $\mathrm{g}[6]=\left(\begin{array}{lllllll}0 & 0 & 0 & 0 & 0 & 0 & 0\end{array}\right)$ & $\mathrm{g}[6] \mathrm{g}[6]$ & $\mathrm{g}[6] \mathrm{g}[6]$ & $\mathrm{g}[6]$ & $\mathrm{g}[6]$ & $g[6]$ \\
\hline
\end{tabular}

Visualization of transformation structures is presented in figure 3 . The structure $G$ shows the selected space "capabilities" of the symmetry group Arithmetic $Z_{7}$ on the plane.


$\mathrm{g}[4]$

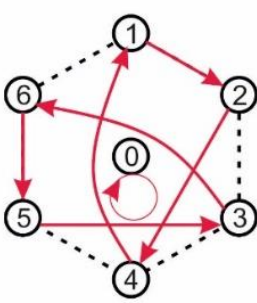

g[1]

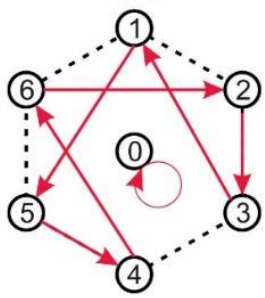

$\mathrm{g}[5]$
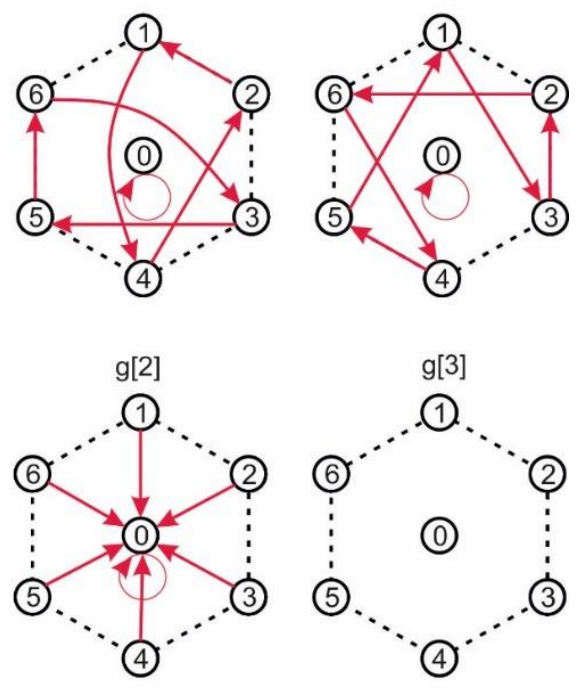

g[6]

G

Fig. 3. The digraphs of the elements of symmetry $Z_{7}$ with the "identity element" of the group $g$ [0] and the "zero" $\mathrm{g}[6]$.

Variant 2. Arithmetic and broken symmetry group $Z_{6}$

As for variant 1 , we analyzed the multiplication table $Z_{6}(\bmod 6)$. The multiplication table 4 in this case showed that the numbers in some rows could be repeated, which means that the operations $g[i]$ were non-permutations. It allowed us to conclude this time, that the multiplication table did not belong to the "Cayley table". In the following we called substitutions the rows and matrices themselves, the lower rows of which they were. Therefore, we were dealing with a broken symmetry group.

The reason for this breaking is obviously explained by the fact that the number 6 has divisors. We calculated the group of broken symmetry using the software "MATRIX" by selecting the second row of the table as the generating element of the binary product group, that is, the operation $\mathrm{g}[1]=(024024)$. We made clear sure the identity of the data recorded in the left and right tables (table 4).

Visualization of transformation structures of arithmetic $Z_{6}$ is presented in figure 4 . The two-dimensional space of "visualization capabilities" $G$, as in the first case for arithmetic $Z_{6}$, was chosen for convenience of analyzing individual transformations of the broken symmetry group and their comparison. Generally it was possible to use both onedimensional (linear) space, and a conical surface as well as other shapes. 
Table 4. Multiplication table $Z_{6}$ (left) and the table of the broken symmetry group of arithmetic $Z_{6}$ (right).

\begin{tabular}{|c|c|c|c|c|c|c|}
\hline$*$ & 0 & 1 & 2 & 3 & 4 & 5 \\
\hline 0 & 0 & 0 & 0 & 0 & 0 & 0 \\
\hline 1 & 0 & 1 & 2 & 3 & 4 & 5 \\
\hline 2 & 0 & 2 & 4 & 0 & 2 & 4 \\
\hline 3 & 0 & 3 & 0 & 3 & 0 & 3 \\
\hline 4 & 0 & 4 & 2 & 0 & 4 & 2 \\
\hline 5 & 0 & 5 & 4 & 3 & 2 & 1 \\
\hline
\end{tabular}

\begin{tabular}{|l|lllllll|}
\hline $\mathrm{g}[0]=\left(\begin{array}{llllllll|}0 & 1 & 2 & 3 & 4 & 5\end{array}\right)$ & $\mathrm{g}[0]$ & $\mathrm{g}[1]$ & $\mathrm{g}[2]$ & $\mathrm{g}[3]$ & $\mathrm{g}[4]$ & $\mathrm{g}[5]$ \\
\hline $\mathrm{g}[1]=\left(\begin{array}{llllllll}0 & 2 & 4 & 0 & 2 & 4\end{array}\right)$ & $\mathrm{g}[1]$ & $\mathrm{g}[2]$ & $\mathrm{g}[1]$ & $\mathrm{g}[2]$ & $\mathrm{g}[5]$ & $\mathrm{g}[5]$ \\
\hline $\mathrm{g}[2]=\left(\begin{array}{lllllll}0 & 4 & 2 & 0 & 4 & 2\end{array}\right)$ & $\mathrm{g}[2]$ & $\mathrm{g}[1]$ & $\mathrm{g}[2]$ & $\mathrm{g}[1]$ & $\mathrm{g}[5]$ & $\mathrm{g}[5]$ \\
\hline $\mathrm{g}[3]=\left(\begin{array}{lllllllll}0 & 5 & 4 & 3 & 2 & 1\end{array}\right)$ & $\mathrm{g}[3]$ & $\mathrm{g}[2]$ & $\mathrm{g}[1]$ & $\mathrm{g}[0]$ & $\mathrm{g}[4]$ & $\mathrm{g}[5]$ \\
\hline $\mathrm{g}[4]=\left(\begin{array}{llllllll}0 & 3 & 0 & 3 & 0 & 3\end{array}\right)$ & $\mathrm{g}[4]$ & $\mathrm{g}[5]$ & $\mathrm{g}[5]$ & $\mathrm{g}[4]$ & $\mathrm{g}[4]$ & $\mathrm{g}[5]$ \\
\hline $\mathrm{g}[5]=\left(\begin{array}{lllllllll}0 & 0 & 0 & 0 & 0 & 0\end{array}\right)$ & $\mathrm{g}[5]$ & $\mathrm{g}[5]$ & $\mathrm{g}[5]$ & $\mathrm{g}[5]$ & $\mathrm{g}[5]$ & $\mathrm{g}[5]$ \\
\hline
\end{tabular}
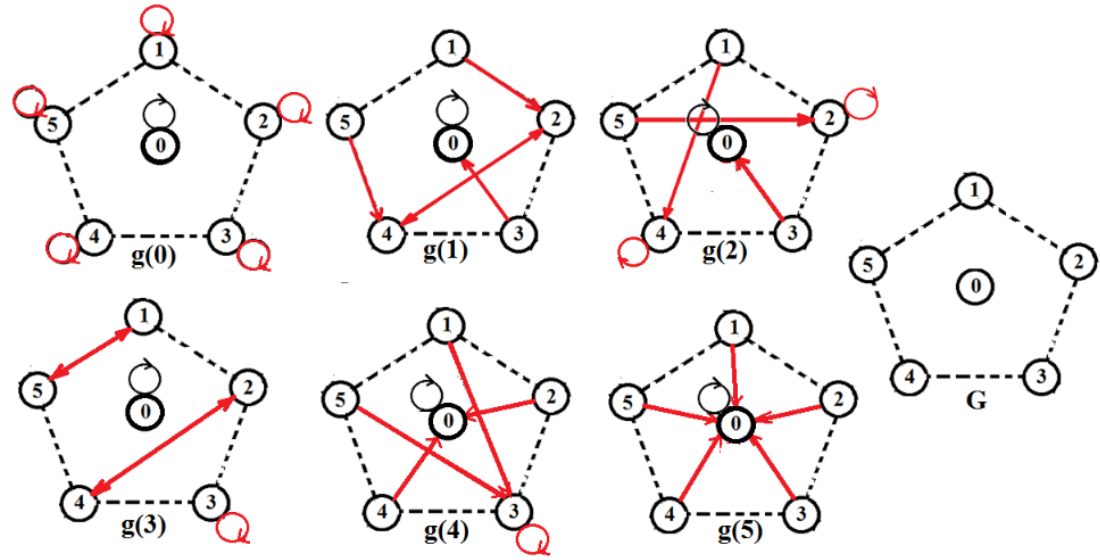

Fig. 4. The digraphs of the elements of broken symmetry $Z_{6}$. G presents two-dimensional space "capabilities".

\subsection{Example 3. The semigroup}

The examples in which a part of the category obeys the axioms of symmetry, and another part has the broken symmetry are more complicated. If one of the pre-requisites for the group is not fulfilled, then the group is broken and turns to be some other algebraic structure. For example, the rejection of the necessity to have an "inverse element" (from the axioms of symmetry) leads to the formation of a set structure, which is called a semigroup [14]. The following table 5 of substitutions in two-line matrices is a simple example of a semigroup. We have presented with more details the results of geometric analysis for properties of the transformation elements (matrices) in this semigroup. The semigroup itself includes both the symmetry subgroup of the regular triangle (which we illustrate geometrically) and various broken symmetry subgroups.

We "visualized" each matrix using the vertices of a regular triangle on the plane as a geometric model, the relationship between the points would be represented by a directed "arc" (digraph). As it was already noted in other examples, it is possible to choose another space for the image of the matrices. In figure 5, we presented the visualization of the structures of all 27 transformations for a semigroup of three points on a plane set. 
Table 5. The set of three substitutions written by matrices, $N=3^{3}$.

\begin{tabular}{|c|c|c|c|c|}
\hline$g[0]=\left(\begin{array}{l}012 \\
012\end{array}\right)$ & $g[1]=\left(\begin{array}{l}012 \\
010\end{array}\right)$ & $g[2]=\left(\begin{array}{l}012 \\
120\end{array}\right)$ & $g[3]=\left(\begin{array}{l}012 \\
121\end{array}\right)$ & $g[4]=\left(\begin{array}{l}012 \\
100\end{array}\right)$ \\
\hline$g[5]=\left(\begin{array}{l}012 \\
101\end{array}\right)$ & $g[6]=\left(\begin{array}{l}012 \\
201\end{array}\right)$ & $g[7]=\left(\begin{array}{l}012 \\
202\end{array}\right)$ & $g[8]=\left(\begin{array}{l}012 \\
211\end{array}\right)$ & $g[9]=\left(\begin{array}{l}012 \\
212\end{array}\right)$ \\
\hline$g[10]=\left(\begin{array}{l}012 \\
001\end{array}\right)$ & $g[11]=\left(\begin{array}{l}012 \\
000\end{array}\right)$ & $g[12]=\left(\begin{array}{l}012 \\
011\end{array}\right)$ & $g[13]=\left(\begin{array}{l}012 \\
022\end{array}\right)$ & $g[14]=\left(\begin{array}{l}012 \\
020\end{array}\right)$ \\
\hline$g[15]=\left(\begin{array}{l}012 \\
112\end{array}\right)$ & $g[16]=\left(\begin{array}{l}012 \\
111\end{array}\right)$ & $g[17]=\left(\begin{array}{l}012 \\
122\end{array}\right)$ & $g[18]=\left(\begin{array}{l}012 \\
110\end{array}\right)$ & $g[19]=\left(\begin{array}{l}012 \\
220\end{array}\right)$ \\
\hline$g[20]=\left(\begin{array}{l}012 \\
222\end{array}\right)$ & $g[21]=\left(\begin{array}{l}012 \\
200\end{array}\right)$ & $g[22]=\left(\begin{array}{l}012 \\
221\end{array}\right)$ & $g[23]=\left(\begin{array}{l}012 \\
002\end{array}\right)$ & $g[24]=\left(\begin{array}{l}012 \\
102\end{array}\right)$ \\
\hline$g[25]=\left(\begin{array}{l}012 \\
021\end{array}\right)$ & $g[26]=\left(\begin{array}{l}012 \\
210\end{array}\right)$ & & & \\
\hline
\end{tabular}
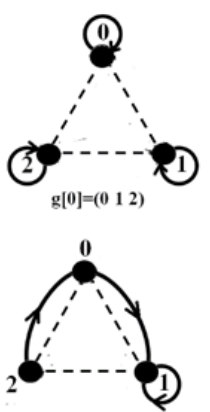

$\mathrm{g}[18]=\left(\begin{array}{lll}1 & 1 & 0\end{array}\right)$

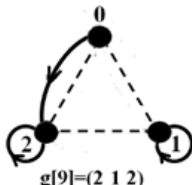

$g[9]=\left(\begin{array}{lll}2 & 1 & 2\end{array}\right)$

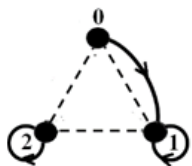

$g\left[\begin{array}{ll}15 \\ =\end{array}=\left(\begin{array}{lll}1 & 1 & 2\end{array}\right)\right.$

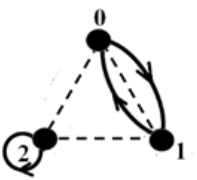

$g[24]=\left(\begin{array}{lll}1 & 0 & 2\end{array}\right)$
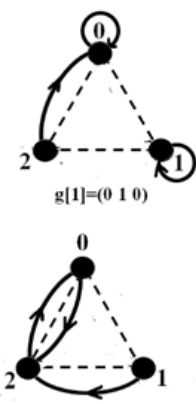

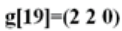

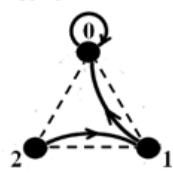

$g[10]=\left(\begin{array}{lll}0 & 0 & 1\end{array}\right)$

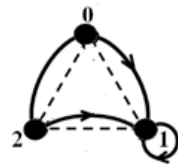

$g\left[\begin{array}{ll}16 \\ =\end{array}=\left(\begin{array}{lll}1 & 1 & 1\end{array}\right)\right.$

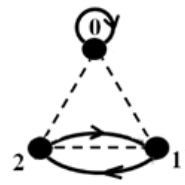

$\mathrm{g} \mid 25]=\left(\begin{array}{lll}0 & 2 & 1\end{array}\right)$

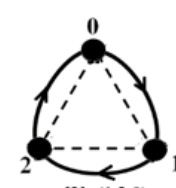

$g[2]=\left(\begin{array}{lll}1 & 2 & 0\end{array}\right)$

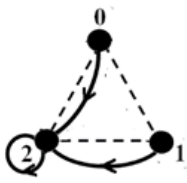

$g[20]=\left(\begin{array}{lll}2 & 2 & 2\end{array}\right)$

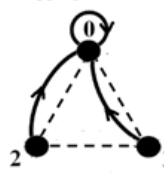

$\mathrm{g}[11]=\left(\begin{array}{lll}0 & 0 & 0\end{array}\right)$

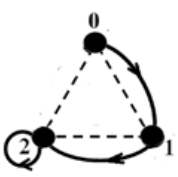

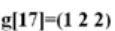

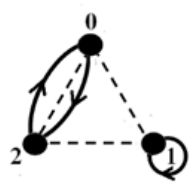

g[26]=( $\left.\begin{array}{lll}2 & 1 & 0\end{array}\right)$

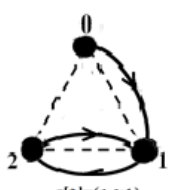

$g[3]=\left(\begin{array}{lll}1 & 2 & 1\end{array}\right)$

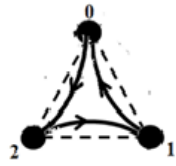

$g|6|=\left(\begin{array}{lll}2 & 0 & 1\end{array}\right)$

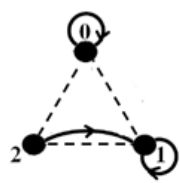

$g[12]=\left(\begin{array}{lll}0 & 1 & 1\end{array}\right)$

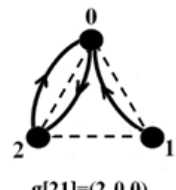

$g[21]=\left(\begin{array}{lll}2 & 0 & 0\end{array}\right)$

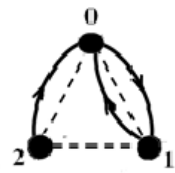

$g\left[\begin{array}{ll}4 \\ \mid\end{array}=\left(\begin{array}{lll}1 & 0 & 0\end{array}\right)\right.$



$g[5]=\left(\begin{array}{lll}1 & 0 & 1\end{array}\right)$

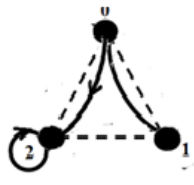

$\mathrm{g} \mid \overline{7}]=\left(\begin{array}{lll}2 & 0 & 2\end{array}\right)$

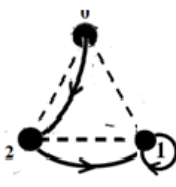

$g\left[8 \mid=\left(\begin{array}{lll}2 & 1 & 1\end{array}\right)\right.$



$g\left[\begin{array}{ll}13 \\ =\end{array}=\left(\begin{array}{lll}0 & 2 & 2\end{array}\right)\right.$
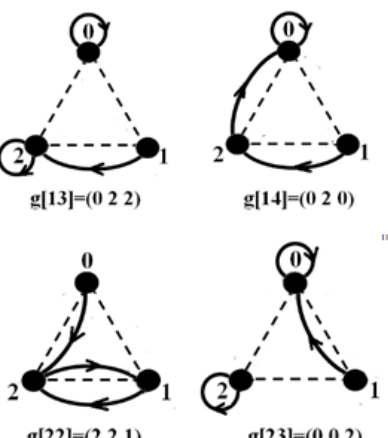

$\mathrm{g}[23]=\left(\begin{array}{lll}0 & 0 & 2\end{array}\right)$

Fig. 5. Visualization of 27 matrix structures for transformations of the semigroup "triangle".

Among this variety of structures, thanks to "visualization", we can distinguish only those that are defined by the symmetry group of the equilateral triangle (figure 6.). The transformations $\mathrm{g}[0], \mathrm{g}[2]$ and $\mathrm{g}$ [6] determine the rotational symmetry of the triangle, and the transformations $g$ [25], g [24] and $g$ [26] characterize the planes of mirror symmetry passing through the vertices of the triangle. The calculation of the triangle symmetry group using the software "MATRIX", carried out separately from other calculations, is presented in table 6. 
Table 6. The Cayley table for the symmetry group of the equilateral triangle.

\begin{tabular}{|c|c|c|}
\hline $\mathrm{g}[0]=\left(\begin{array}{lll}0 & 1 & 2\end{array}\right)$ & $\mathrm{g}[0] \mathrm{g}[1] \mathrm{g}[2] \mathrm{g}[3] \mathrm{g}[4] \mathrm{g}[5]$ & Rotation by 360 degrees \\
\hline $\mathrm{g}\left[\begin{array}{lll}1] & =\left(\begin{array}{lll}0 & 2 & 1\end{array}\right)\end{array}\right.$ & $\mathrm{g}[1] \mathrm{g}[0] \mathrm{g}[3] \mathrm{g}[2] \mathrm{g}[5] \mathrm{g}[4]$ & Mirror symmetry (plane $m_{l}$ ) \\
\hline$g[2]=\left(\begin{array}{lll}1 & 0 & 2\end{array}\right)$ & $\mathrm{g}[2] \mathrm{g}[4] \mathrm{g}[0] \mathrm{g}[5] \mathrm{g}[1] \mathrm{g}[3]$ & Mirror symmetry (plane $m_{2}$ ) \\
\hline $\mathrm{g}[3]=\left(\begin{array}{lll}1 & 2 & 0\end{array}\right)$ & $\mathrm{g}[3] \mathrm{g}[5] \mathrm{g}[1] \mathrm{g}[4] \mathrm{g}[0] \mathrm{g}[2]$ & Rotation by120 degrees \\
\hline 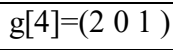 & $\mathrm{g}[4] \mathrm{g}[2] \mathrm{g}[5] \mathrm{g}[0] \mathrm{g}[3] \mathrm{g}[1]$ & Rotation by 240 degrees \\
\hline$g[5]=\left(\begin{array}{lll}2 & 1 & 0\end{array}\right)$ & $\mathrm{g}[5] \mathrm{g}[3] \mathrm{g}[4] \mathrm{g}[1] \mathrm{g}[2] \mathrm{g}[0]$ & Mirror symmetry (plane $m_{3}$ ) \\
\hline
\end{tabular}

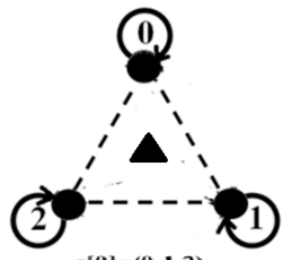

$g\left[\begin{array}{lll}0 & =\end{array}=\left(\begin{array}{ll}0 & 1\end{array}\right)\right.$

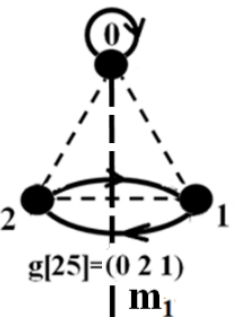

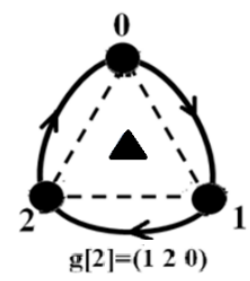

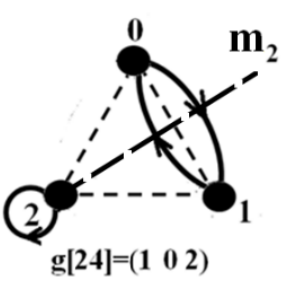



$\mathrm{g}\left[\mathbf{6} \mid=\left(\begin{array}{lll}2 & 0 & 1\end{array}\right)\right.$

Fig. 6. The visualization of transformations in the symmetry group of a regular triangle.

After visualization the transformations with broken symmetry can also be divided into separate subsets of operations $g$ [i], which have the same structure $\mathrm{S}$ up to rotation and mirror symmetry in the plane.

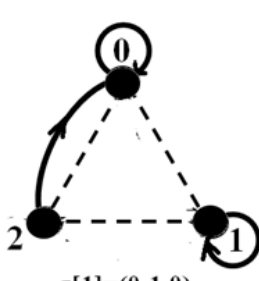

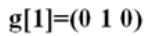

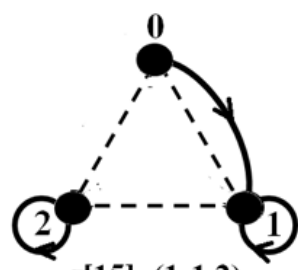

$\mathrm{g}[\mathbf{1 5}]=\left(\begin{array}{lll}1 & 1 & 2\end{array}\right)$

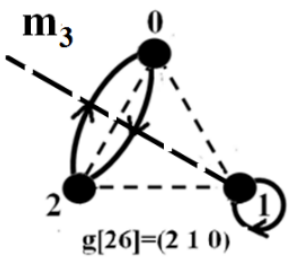

$g[26]=\left(\begin{array}{lll}2 & 1 & 0\end{array}\right)$

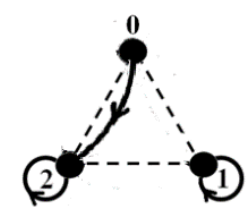

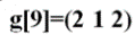

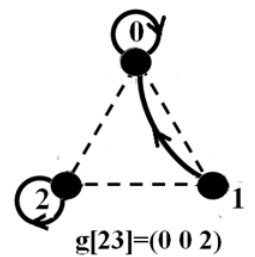

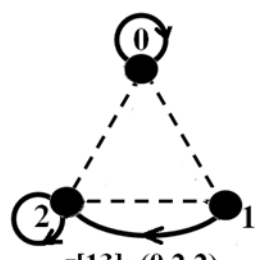

$g\left[\begin{array}{lll}13 \\ 0\end{array}\right]\left(\begin{array}{lll}0 & 2 & 2\end{array}\right)$

Fig. 7. The set of identical structures of the broken symmetry subgroup in a semigroup.

It should be immediately noted (according to figure 6 and figure 7) that both symmetric structures and structures with broken symmetry have an "internal" unity, which can be called "hidden" symmetry. When superimposing points and operations are defined in 
structures with broken symmetry g [i] (figure 7), we obtain the structure from the list of symmetric ones shown in figure 6 . For example, the union of the structures $g$ [1] and $g$ [9] leads to the structure $g[26]: S(g[1]) \cup S(g[9]) \in S(g[26])$

In a simplified form, this can be written as follows: $g[1]+g[9]=g[26]$. Thus, the operation of adding (superimposing) transformations can be introduced. By analogy, we can write: $g[15]+\mathrm{g}[23]=\mathrm{g}[24]$ и $\mathrm{g}[12]+\mathrm{g}[13]=\mathrm{g}[25]$.

Without an image of the structures of operations, that is, without their "visualization", it is practically impossible to find relationship between them. After the "visualization" procedure, there is no need to prove "existence theorems" of various relations between structures in the semigroup.

\subsection{Example 4. The deoxyribonucleic acid (DNA) in the broken symmetry group}

A high moisture DNA molecule has B-form. Under certain physiological conditions (low salt concentration, high degree of hydration), the predominant structural type of DNA is represented precisely by the B-form shown in figure 8 (the basic form of double-stranded DNA in the Watson-Crick model [15]).

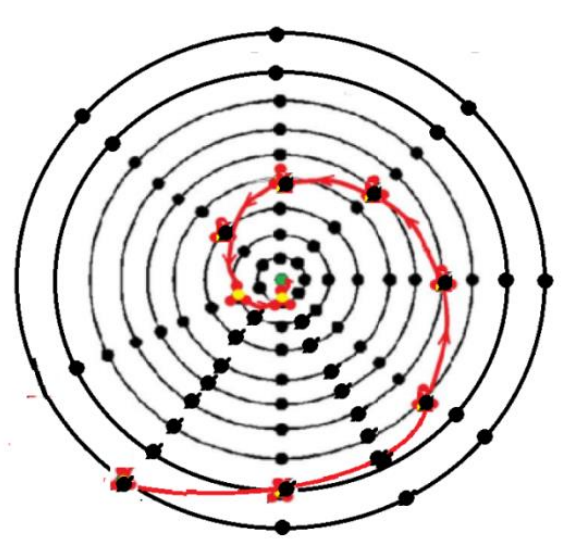

a

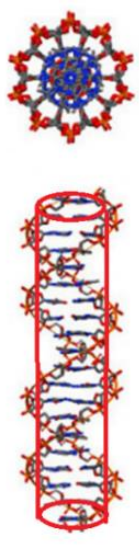

$\mathrm{b}$

Fig. 8. (a) A "top view" of the twisted helix of the phosphodiester DNA core placed on the outer surface of the cone (b) "Double helix" on the surface of the "cylindrical space"- DNA nanocluster.

The helix pitch of this molecule is $3.4 \mathrm{~nm} ; 10$ complementary pairs - nitrogen bases ("stacks") - are accounted for. Nitrogen bases are connected by hydrogen bonds between two opposite "coins" of the stacks, and are surrounded by two ribbons of the phosphodiester core twisted into a right spiral [15]. The planes of the nitrogenous bases are perpendicular to the axis of the spiral. The rotation between adjacent complementary pairs relative to each other is $36^{\circ}$. The diameter of the helix is $20 \AA$, where the purine nucleotide is $12 \AA$ and the pyrimidine nucleotide is $8 \AA$. If we assign now an index from 0 to 9 to each complementary pair and assign a substitution (on the bottom line) along the helix (figure

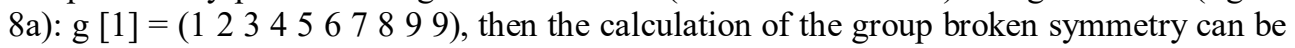
produced similarly to the examples considered (table 7).

For a double helix, the structure is easily calculated by replacing each point of a single helix with two points. To calculate the DNA (a helix-10 steps in 2, 20 elements are obtained). Then the structure of the double-helix will look as it is presented in table 8 . 
Table 7. The group of a single-entry canonical DNA helix (B-form).

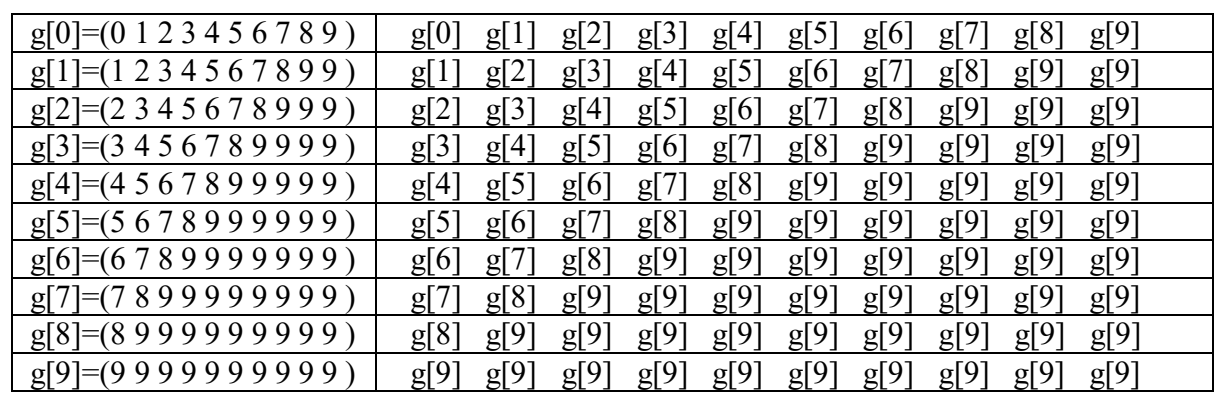

Table 8. The calculation of a two-way DNA B-form.

\begin{tabular}{|c|c|}
\hline 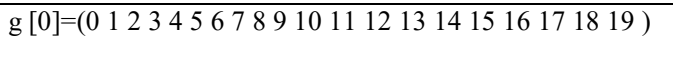 & $\begin{array}{llllllll}\mathrm{g}[0] & \mathrm{g}[1] & \mathrm{g}[2] & \mathrm{g}[3] & \mathrm{g}[4] & \mathrm{g}[5] & \mathrm{g}[6] & \mathrm{g}[7] \\
\mathrm{g}[8] & \mathrm{g}[9] & \end{array}$ \\
\hline$g[1]=(234566789101112131415161718191819$ & $\begin{array}{llllllll}\mathrm{g}[1] & \mathrm{g}[2] & \mathrm{g}[3] & \mathrm{g}[4] & \mathrm{g}[5] & \mathrm{g}[6] & \mathrm{g}[7] & \mathrm{g}[8] \\
\mathrm{g}[9] & \mathrm{g}[9] & & & & & & \\
\end{array}$ \\
\hline 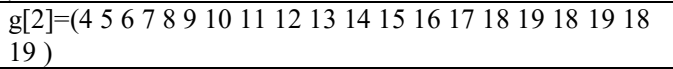 & $\begin{array}{llllllll}\mathrm{g}[2] & \mathrm{g}[3] & \mathrm{g}[4] & \mathrm{g}[5] & \mathrm{g}[6] & \mathrm{g}[7] & \mathrm{g}[8] & \mathrm{g}[9] \\
\mathrm{g}[9] & \mathrm{g}[9] & & & & & \\
\end{array}$ \\
\hline $\begin{array}{l}\text { g[3]=(6 } 7891011121314151617181918191819 \\
1819)\end{array}$ & $\begin{array}{llllllll}\mathrm{g}[3] & \mathrm{g}[4] & \mathrm{g}[5] & \mathrm{g}[6] & \mathrm{g}[7] & \mathrm{g}[8] & \mathrm{g}[9] & \mathrm{g}[9] \\
\mathrm{g}[9] & \mathrm{g}[9] & & & & & & \\
\end{array}$ \\
\hline 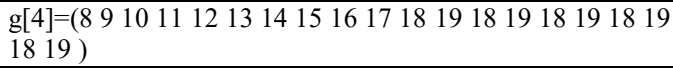 & $\begin{array}{llllllll}\mathrm{g}[4] & \mathrm{g}[5] & \mathrm{g}[6] & \mathrm{g}[7] & \mathrm{g}[8] & \mathrm{g}[9] & \mathrm{g}[9] & \mathrm{g}[9] \\
\mathrm{g}[9] & \mathrm{g}[9] & & & & & & \\
\end{array}$ \\
\hline 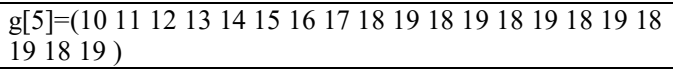 & $\begin{array}{llllllll}\mathrm{g}[5] & \mathrm{g}[6] & \mathrm{g}[7] & \mathrm{g}[8] & \mathrm{g}[9] & \mathrm{g}[9] & \mathrm{g}[9] & \mathrm{g}[9] \\
\mathrm{g}[9] & \mathrm{g}[9] & & & & & \\
\end{array}$ \\
\hline $\begin{array}{l}\text { g[6]=(12 131415 } 16171819181918191819181918 \\
191819)\end{array}$ & $\begin{array}{lllll}\mathrm{g}[6] & \mathrm{g}[7] & \mathrm{g}[8] & \mathrm{g}[9] & \mathrm{g}[9] \\
\mathrm{g}[9] & \mathrm{g}[9] & & \\
\end{array}$ \\
\hline $\begin{array}{l}\text { g[7] }=(1415161718191819181918191819181918 \\
191819)\end{array}$ & $\begin{array}{llllllll}\mathrm{g}[7] & \mathrm{g}[8] & \mathrm{g}[9] & \mathrm{g}[9] & \mathrm{g}[9] & \mathrm{g}[9] & \mathrm{g}[9] & \mathrm{g}[9] \\
\mathrm{g}[9] & \mathrm{g}[9] & & & & & & \\
\end{array}$ \\
\hline 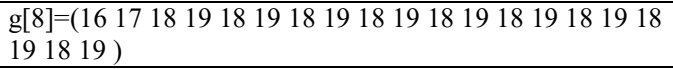 & $\begin{array}{lllllll}\mathrm{g}[8] & \mathrm{g}[9] & \mathrm{g}[9] & \mathrm{g}[9] & \mathrm{g}[9] & \mathrm{g}[9] & \mathrm{g}[9] \\
\mathrm{g}[9] & \mathrm{g}[9] & & & & \\
\end{array}$ \\
\hline $\begin{array}{l}\text { g[9]=(18 } 19181918191819181918191819181918 \\
191819)\end{array}$ & $\begin{array}{lllllll}\mathrm{g}[9] & \mathrm{g}[9] & \mathrm{g}[9] & \mathrm{g}[9] & \mathrm{g}[9] & \mathrm{g}[9] & \mathrm{g}[9] \\
\mathrm{g}[9] & \mathrm{g}[9] & & & & \\
\end{array}$ \\
\hline
\end{tabular}

Figure 8 shows two options for the "existence" of a helix: (A) on the surface of a cone, which in a projection can depict a helix on a plane or a helix on the surface of a cylinder (B). Thus, virtually, there may be several variants for choosing the "space of possibilities" and the solution of each problem requires experimental research. In the last example, nature has chosen the variant (B), which is proved by X-ray diffraction analysis. The three-way helix model for a DNA molecule is known as well as the hypothesis of Linus Pauling and others. Within the broken symmetry groups, a three-way helix, as a "project", is calculated elementarily.

\section{Conclusion}

In the presented work, it is shown that both symmetry and broken symmetry groups find their application in the description of states and transformations in natural and abstract mathematical objects. They can be transferred to any system as models of development and evolution as well. 230 space symmetry groups, the quest for which was just for pure mathematical interest, became the basis for the classification and decoding of solids with a similar structure by X-ray diffraction analysis. Broken symmetry groups make it possible to visualize the described objects with the help of digraphs, which in its way make it possible to reveal at first glance the hidden similarity of the internal structure of some objects and to establish relationship between them. The principles of conservation and symmetry breaking are the main methodological and practical tools for analysis of systems at any level. 
The main theoretical and practical results of the studies were obtained with the support from the Russian Foundation for Basic Researcher under the grant No. 18-07-00170.

\section{Reference}

1. Bell J L 1981 The British Journal for the Philosophy of Science 32(4) 349

2. Howson A G 1972 A Handbook of Terms used in Algebra and Analysis (Cambridge University Press)

3. Bang-Jensen J, Gutin G Z 2009 Springer-Verlag London Limited 87 (795) doi: 10.1007/978-1-84800-998-1

4. Conway J H, Sloane N J A 1999 Sphere Packing, Lattices and Groups (New York: Springer Science+Business Media) p 681

5. Shubnikov A V, Koptsik V A 1974 Symmetry in science and art (New York: Springer US Plenum Press) p 420

6. Higgs P W 1964 Physical Review Letters 13508

7. Francois Englert 2014 Pac. Phys. Newslett. 03(1) 54

8. Antipov A A, Arakelian S M, Kutrovskaya S V, Kucherik A O, Rau V G, Zimin S P 2013 Perspective Materials (Moscow: LLC Intercontact Science) p 304

9. Maleev A V, Zhuravlev V G, Shutov A V, Rau V G Software package for the study of coordination environments in the layer-by-layer growth model of connected graphs No.2013619399

10. Rau V G, Pugaev A A, Rau T F, Maleev A V 2009 Crystallography Reports 54(7) 28

11. Martin T P, Naher U, Bergmann T et al 1991 Chem. Phys. Lett. 176343

12. Liu Hao-yang, Zou Xian-wu, Ren Da-zhi, Jin Zhun-zhi 2000 Wuhan Univ. J. Nat. Sci. 5301 doi: 10.1007/BF02830140

13. Rau V G, Lomtev L A, Rau T F, Nikitin O R 2016 Proceedings of the Congress Digest of the First Russian Crystallography Congress (Moscow)

14. Rau V G, Lomtev L A, Rau T F, Nikitin O R 2018 J. Struct. Chem. 59120

15. Rau V G, Togunov I, Rau T F, Polyakov S V 2018 Symmetry 10(10) 440

16. Yaglom I M 1978 An unusual algebra. Little Mathematics Library (Mir Publishers)

17. Rau V G, Lomtev L A, Rau T F, Gerasimov K A 2018 Software patent for computers “MATRIX” No 2018664999

18. Rau V G, Nikitin O R, Gorshkov K A, Saleh H M, Rau T F 2018 Moscow Workshop on Electronic and Networking Technologies (MWENT) doi: 10.1109/MWENT.2018.8337202

19. Blyth T S 1975 Set Theory and Abstract Algebra (Longman Mathematical Texts)

20. Watson J, Crick F 1953 Nature 171(4356) 737 